\title{
Numerical study of heat and water vapour exchanges inside a green roof building in a high irradiation area for passive cooling purpose
}

\author{
Hodo-Abalo SAMAH ${ }^{1,2\left[\text { https://orcid.org/0000-0002-0698-4843] } \text { N'Detigma KATA }^{1} \text {, Kodjo KPODE }\right.}{ }^{1,2}$, \\ Magolmèèna BANNA ${ }^{2}$, and Bekacem ZEGHMATI ${ }^{3}$ \\ ${ }^{1}$ Laboratoire Matériaux et Energie Renouvelable et Environnement (LaMERE), Université de Kara, Togo \\ ${ }^{2}$ Laboratoire sur l'Energie solaire LES/GPTE, Université de Lomé, Togo \\ ${ }^{3}$ Laboratoire de Mathématique et Physique des Systèmes, Université de Perpignan Via Domitia, France
}

\begin{abstract}
Vegetation cover provides shading and protects the soil beneath them from warming. Vegetation can be used as passive cooling technique that reduces the thermal load of a building. A numerical study has been carried out on laminar double-diffusive mixed convection in a green roof enclosure. The model is equipped with inlet and outlet openings for air removal while the left vertical wall is heated and partially saturated with water for indoor air humidification. The mathematical model is governed by the two-dimensional continuity, momentum, energy and concentration equations. Transfer equations are solved using a finite difference scheme and Thomas algorithm. The model was applied for the simulation of a building with green roof in Togolese climate conditions. Results showed that, the flow structure is a mixed convection type, but the isotherms et iso-concentration distributions reveal a vertical stratification of the temperatures and the relative humidity. To predict heat transfers inside the cavity, a correlation has been established for the estimation of the average Nusselt number as a function of the Leaf Area Index and Reynolds number under solar heat flux of $350 \mathrm{~W} \cdot \mathrm{m}^{-2}$, the average in case of Togo. It was found that a larger Leaf Area Index reduces the solar flux penetration and therefore, reduces significantly heat transfer inside the enclosure and then stabilizes it temperature. For the LAl equal to 3 , the indoor air fluctuates around $26^{\circ} \mathrm{C}$ and the relative humidity range is found to be $50 \%-60 \%$ under solar heat flux of $350 \mathrm{~W} \cdot \mathrm{m}^{-2}$.
\end{abstract}

Keywords: Leaf Area Index; Nusselt number; Sherwood number; passive cooling.

\section{Introduction}

Natural cooling techniques have been used over the centuries and their application has started to spread throughout the world, particularly in tropical regions where inside temperatures in buildings are far beyond the comfortable conditions. The introduction of mechanical air conditioning systems into the building, with their great energy expenditure, has become the standard alternative used to natural cooling. Many studies regarding this problematic are developed as ROOFSOL research project [1-4], which focused on the theoretical and experimental analysis of different roof solutions for cooling in arid region, mainly based on evaporative and radiative cooling principles. The green roof technique is also able to reduce the energy consumption and to improve the internal comfort in areas characterized by high temperature and irradiance values during the day [5-7]. With rapid urbanization, there has been high growth in population and building construction in cities. A high concentration of buildings actually raises many environmental issues, such as the Urban 
Heat Island effect. The Urban Heat Island effect started mainly because of the loss of green areas in the urban environment. Plants when strategically placed around roofs can be considered a complement of urban greens. This natural solution also contributes to the thermal benefits in buildings and their surrounding environments. Greenery placed around buildings serves to reduce the surface temperature through direct shading of hard surfaces as well as cool the ambient air through absorbing solar heat for transpiration and photosynthesis. The shaded surfaces also emit less long-wave radiation due to lower surface temperature [8]. All these contribute to lowering energy consumption for cooling and mitigating Urban Heat Island effect in the urban environment. Many studies concerning the energy effectiveness of green roofs are based on the development of complex mathematical models [9-11] which involve an understanding of the characteristics of the vegetation and the substrate [12-14]. On the contrary, research which is based on the observation of monitoring data often refers to short periods of analysis and the results obtained, although of great interest for understanding the behaviour of the type of roof analysed, are difficult to extrapolate for other contexts and for other solutions. Furthermore, in most studies the green roof is considered as a single unit made up of plants and substrate and is always studied when there is the greatest density of vegetation, without bearing in mind that, unless it is a pre-vegetated green roof system, the vegetation takes time to develop after being installed and that the plants may die and the roof may have no vegetation for a certain period of time. In West Africa context, green roof is not investigated or poorly investigated. So modeling a vegetalised roof should be useful for engineer in optimization of such a passive system in practical buildings. Therefore, the aims of this work are to analyse the impact of vegetation density on the dynamic of heat and mass transfer inside a vegetalised building under Togolese climate conditions. The green roof potential was explored through the determination of its effect on the Nusselt number and the indoor temperature fluctuations.

\section{Model description and assumptions}

The domain under analysis is as sketched in Figure 1, a square two-dimensional cavity under the influence of a gravitational field. The heat flux imposed at the top wall is a fraction of solar heat transmitted into the cavity by the planted roof.
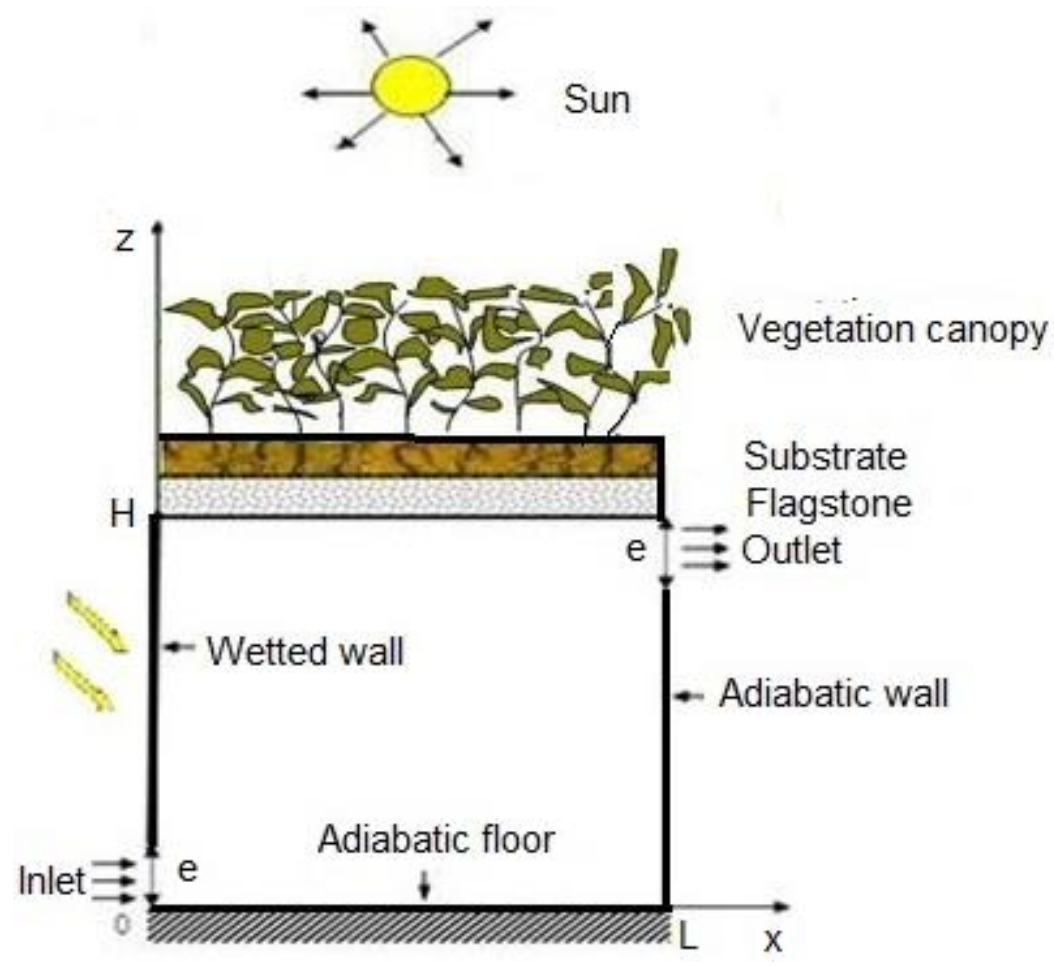

Figure 1. A schematic diagram for the problem. 
The left vertical wall is partially heated and saturated with water. The bottom and the right vertical walls are assumed to be adiabatic. All side walls are impermeable. The inflow opening of size $e$ is located on the lower left vertical wall while the location of the equal sized outflow opening is at the top of the right vertical wall as shown in Figure 1. Fresh air is injected at low speed through the inlet opening in horizontal direction and then the polluted hot air eliminated from the outlet opening at the right side wall. In this paper, the planted roof model is characterized by the Solar Heat gain Factor (SHF) defined as the ratio of the transmitted solar energy into the interior of the enclosure (through the complex roof including the vegetation canopy, the substrate and the flagstone support) to incident solar energy. The previous studies [15] proposed a correlation to calculate SHF as a function of Biot number (Bi) and the Leaf Area Index (LAl).

$$
S H F=\sigma \exp \left(-\frac{L A I}{\delta}\right)+\eta
$$

Where:

$\sigma=97.48257 \exp \left(-\frac{B i}{3.27898}\right)+8.07878$

$\delta=-0.19839+0.14606 B_{i}-0.00693 B_{i}^{2}+0.00021 B_{i}^{3}-2.916210^{-6} B_{i}^{4}$

$\eta=1.98266$

$B_{i}$ is the Biot number

Inside the enclosure, the governing momentum, energy and water vapour conservation equations have been presented for double-diffusive mixed convective flows driven by the combined effect of the internal buoyancy induced by temperature and concentration differences and the external mechanically driven forced flow from the inlet opening. The following assumptions are made in the analysis:

- The laminar airflow is two dimensional;

- Fluids are incompressible and isotropic;

- Thermo physical proprieties of the fluids are assumed to be constant except the density which obeys the Boussinesq approximation;

- Viscous heat dissipation is neglected.

Under these assumptions, the dimensionless governing equations are written in terms of vorticity and stream function formulation.

The heat and mass transfer rates on heat and mass source walls are described by the Nusselt and Sherwood average numbers, respectively as follows:

- on the top wall

$N u_{a v}=\int_{0}^{1} N_{u 1}(X) d X$

where local Nusselt is calculated as follow:

$N_{u 1}(X)=\left.\frac{1}{\Theta}\right|_{Z=1}$

- on the left wall

Local Nusselt and Sherwood numbers are calculated as follows:

$N_{u 2}(Z)=\left.\frac{1}{\Theta}\right|_{X=0}$

$S_{C}(Z)=\left.\frac{1}{C^{*}}\right|_{X=0}$

Reynolds number is defined as follow:

$R_{e}=\frac{u_{0} H}{v}$ 


\section{Numerical procedure and code validation}

Transfer equations with appropriate boundary conditions are solved numerically by using an implicit finite difference method. The Thomas algorithm is employed to solve the algebraic equations. The diffusion terms are approximated by the central finite difference scheme and the implicit procedure to discretize the temporal derivatives is retained.

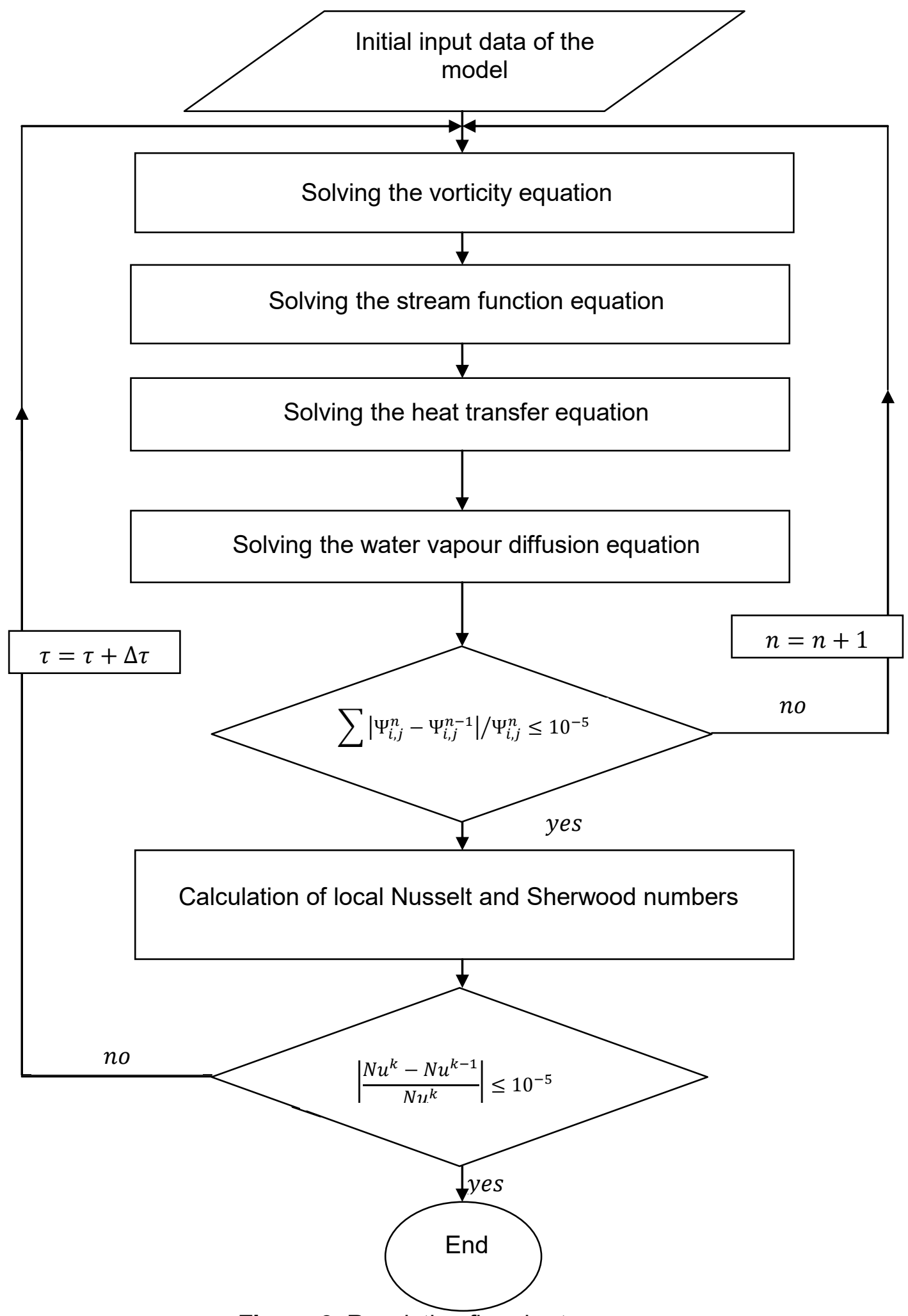

Figure 2. Resolution flowchart 
The determination of the optimum mesh which represents a compromise between the criterion of stability Thomas algorithm and Gauss-Seidel method and an acceptable memory occupation was carried out by analyzing the influence of several steps of space and time on the mean Nusselt and Sherwood numbers. The following time and spatial steps $\Delta t=0.0025 \mathrm{~s}$ and $\Delta X=0.0025 \mathrm{~m}, \Delta Z=0.0025 \mathrm{~m}$ are respectively retained. Successive iterations were applied and the solution is considered satisfactory when the following convergence criterion is verified for each time:

$$
\sum\left|\Psi_{i, j}^{n}-\Psi_{i, j}^{n-1}\right| / \Psi_{i, j}^{n} \leq 10^{-5}
$$

where $\Psi$ is a stream function

Figure 2 gives an overview of how the numerical resolution of the systems of algebrics equations associated with our problem is carried out.To ensure the convergence of the numerical solution to the exact solution, the grid size has been optimized, so results are independent of grid size. Furthermore, in order to verify the accuracy of our numerical procedure, we tested our algorithm based on the grid size $81 \times 81$ for a square enclosure with a discrete bottom wall heated and saturated with water. This computation of Sumon Saha [16] for mixed convection heat transfer inside a vented square cavity was validated and found to agree quite well. Similar distribution of streamlines is obtained as shown in figure 3.

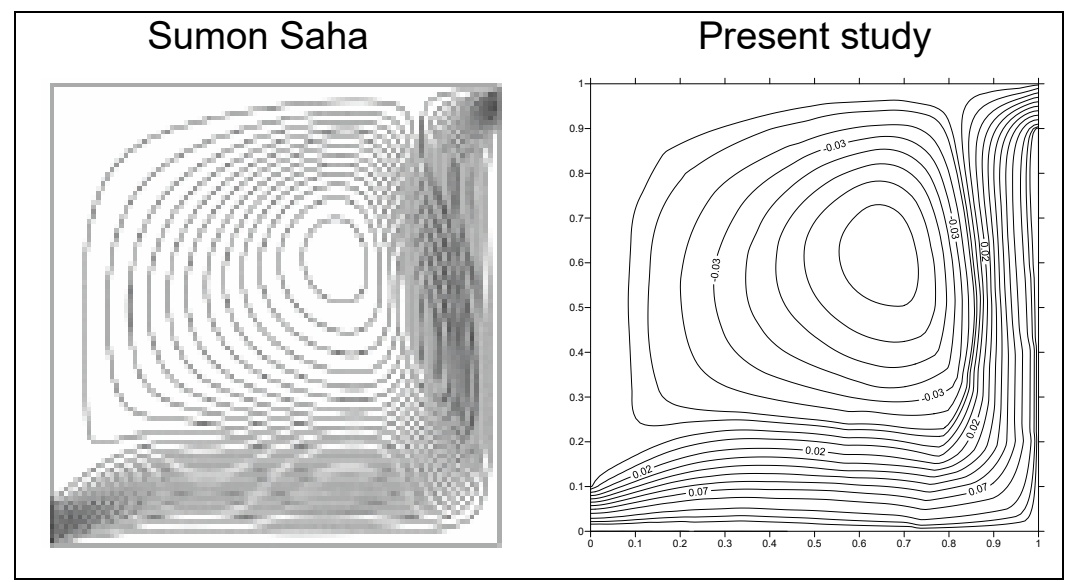

Figure 3. Comparison of streamlines with the results of Sumon Saha [16]

\section{Results and discussion}

Results were obtained for mixed convective flow and the Reynolds number is determined by the inlet wind speed. The Leaf Area Index (LAI) is chosen as the main parameter for the study. Then, particular attention is paid to the effects of this governing parameter LAI on the indoor air mixed convection. The range of LAI values used for the simulations is $1 \leq L A I \leq 6$. The objective of this study is to examine the heat transfer and the fluid flow characteristics due to mixed convection inside a square vented enclosure with a constant heat source on the top wall which represents the planted roof. The resulting flow structure is analyzed to provide a fundamental understanding of the effect of the Leaf Area Index and Reynolds number on the flow, thermal and water vapour concentration fields. Important dimensionless parameters for the present study are Nusselt and Sherwood numbers, on which the effect of the LAl and the Reynolds number is studied. The flow structure, the heat and mass transfers in the cavity are given in terms of streamline, isotherms and iso concentration lines. Figures 4 and 5 showed the effect of Leaf Area Index on characteristics fields for different solar heat flux amount reaching the planted roof. The airflow is characterized by open lines and pockets of fluid formed at the lower part of the right insulated wall. 


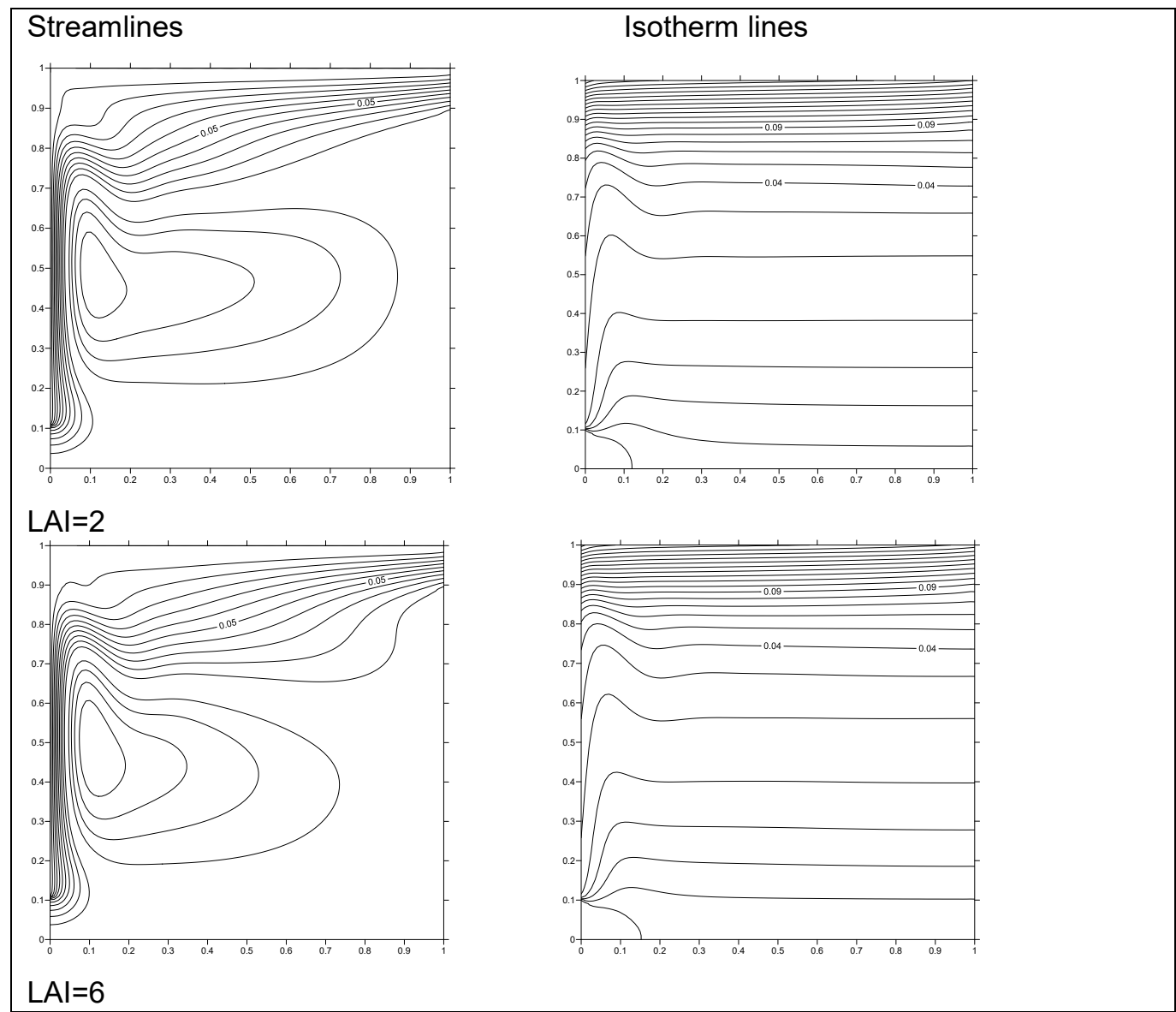

Figure 4. Streamlines and isotherm lines for $R n\left(Z_{R}\right)=200 \mathrm{~W} / \mathrm{m}^{2}$

It can be seen from figure 4 that the natural convection effect is present but remains relatively weak for higher values of the Leaf Area Index since open lines characterizing the imposed flow are still slightly dominant. The lower recirculation zone spreads and thereby squeezes the induced flow path resulting in almost the same kinetic energy in the bulk induced flow as that of the inlet section. Convection heat transfer induces the growth of the recirculation cell resulting in the faster removal of heat and mass from the heat and water sources. When the buoyancy force increases with the increase of heat flux and concentration gradients, the recirculation zone begins to develop by absorbing thermal energy through induced forced flow. Thereby the squeezed induced flow covers the whole of the heat and water source at low LAI. Similarly, the effect of natural convection on the temperature and water vapour concentration distribution is characterized by the displacement of the isotherm, isoconcentration and isohumidity fronts throughout the cavity. But, since the induced flow sweeps over the heat and water vapour concentration level to the left upper corner of the cavity decrease indicating a better heat and water vapour transfer. As transfer numbers increase nonlinearily, isotherm, isoconcentration and isohumidity lines become higher and plume formation is profound, indicating a well-established natural convection double diffusive flow. In this case, heat conduction in the fluid becomes more important than convection heat transfer (isotherm lines of figure 4). Furthermore, the distributions of isotherms and isoconcentrations describe a vertical stratification of air temperatures and humidity. 


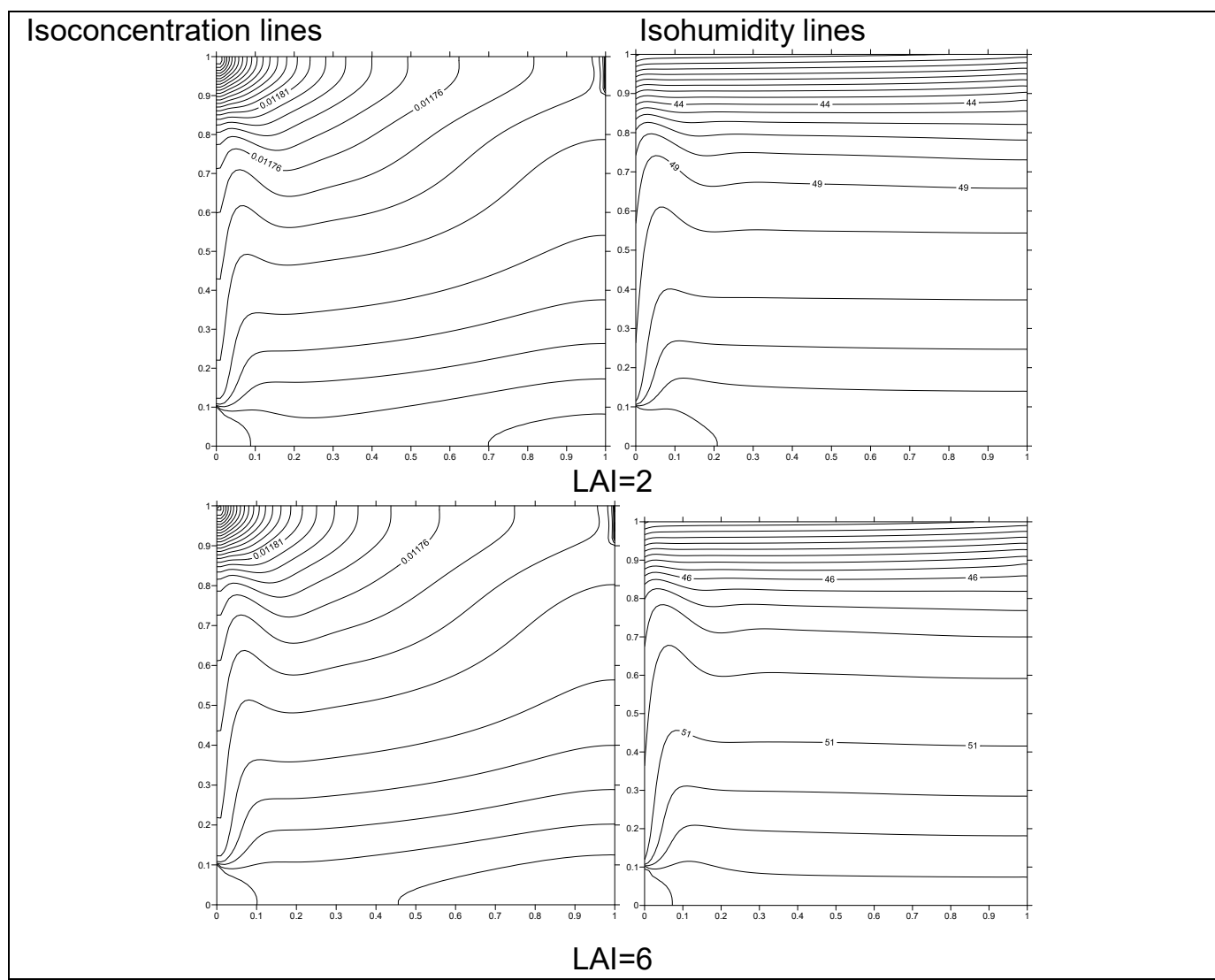

Figure 5. Isoconcentration lines and isohumidity lines for $R n\left(Z_{R}\right)=200 \mathrm{~W} / \mathrm{m}^{2}$

Increasing in solar heat flux reaching on a building leads to intensify simultaneously heat and mass transfers between the hot walls and the air in the cavity. Thus, the local Nusselt and Sherwood numbers increase nonlinearly when the solar flux on the walls increases as shown in figures 6 and 7 .

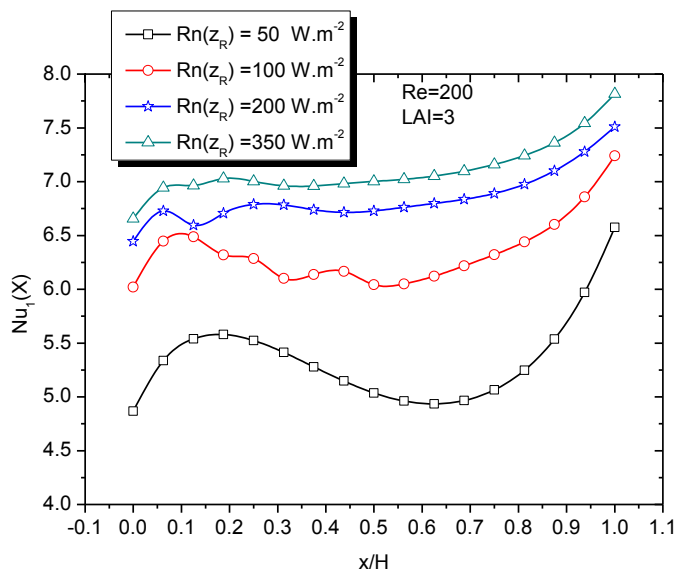

Figure 6. Effect of solar flux density on the variation of the local Nusselt number for upper wall of the cavity

For LAl equal to 3, figure 8 shows the variation in average temperature and relative humidity inside the cavity for different values of the solar flux density. This variation clearly indicates that the internal temperature undergoes very few fluctuations around $26{ }^{\circ} \mathrm{C}$ for solar flux of $350 \mathrm{~W} . \mathrm{m}^{-2}$ while the relative humidity rate is between $50 \%$ and $60 \%$. 

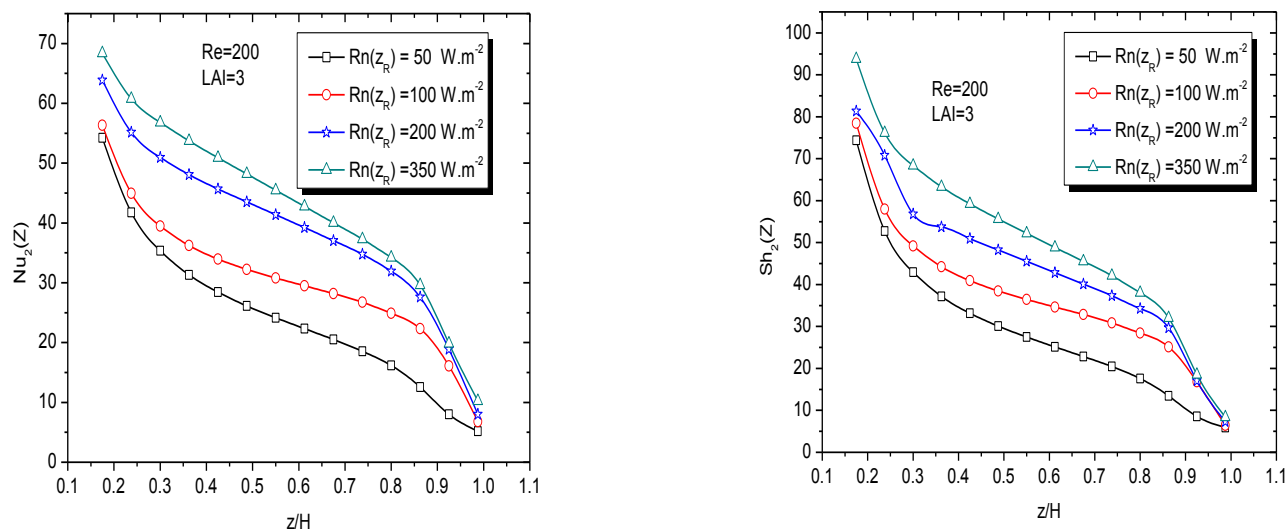

Figure 7. Influence of solar flux density on the variation of local Nusselt and Sherwood numbers for wetted wall
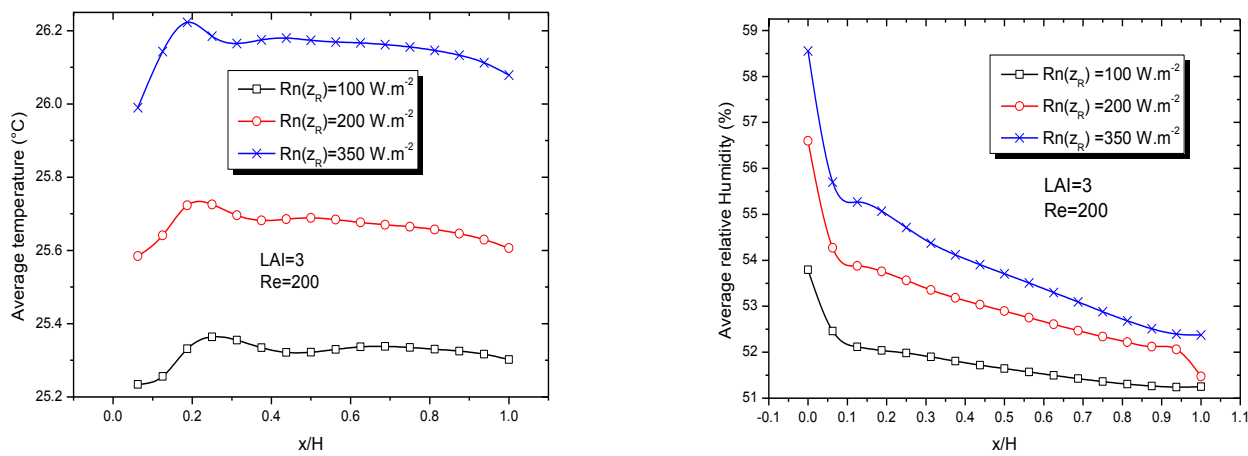

Figure 8. Variation in average temperature and relative humidity

To promote the technique of the vegetated roof, it seemed useful to establish a relation between the average Nusselt number, the Reynolds number and the Leaf Area Index. This relationship could contribute, during the architectural design, to facilitate the modeling and optimization of the characteristic quantities of this kind of building. The density of the solar flux being very variable during the day, heat exchanges between the vegetated slab and the indoor air has been expressed in the form of a heat transfer correlation as a fuction of the LAl and the Reynolds number for a solar flux density of $350 \mathrm{~W} . \mathrm{m}^{-2}$ which represents an average value in Togolese climate conditions. According to profiles obtained, a polynomial expression has been proposed and tested.

$$
N u_{1 m b}=N u_{0 b}+\beta_{0}(L A I)+\beta_{1} \cdot\left(\beta_{2}{ }^{L A I}\right)
$$

Where:

$$
\begin{aligned}
& N u_{0 b}=4.32328+0.01435 R e \\
& \beta_{0}=0,01173-0.00008 R e+1,7041 \cdot 10^{-10} R e^{2}-1,1285 \cdot 10^{-10} R e^{3} \\
& \beta_{1}=-0,09443+0,00567 R e-3,5796 \cdot 10^{-6} R e^{2} \\
& \overline{\beta_{2}}=0,3248
\end{aligned}
$$


Table 1 presents the values of the coefficients $N u_{0 b}, \beta_{0}$ and $\beta_{1}$ for different values of Reynolds number. Values of the Reynolds number are calculated with increments in inlet air velocity to take into account natural and forced airflows in the cavity. The range of the Reynolds number $\mathrm{Re}$ and the $\mathrm{LAl}$ are respectively: $100 \leq R_{e} \leq 600$ and $0.5 \leq R_{e} \leq 7.5$.

Table 1. Values of coefficients as a function of the Reynolds number.

\begin{tabular}{|l|l|l|l|l|}
\hline $\mathbf{R e}$ & $\mathrm{Nu}_{0 \mathrm{~b}}$ & $\beta_{0}$ & $\beta_{1}$ & $\beta_{2}$ \\
\hline 100 & 5,65929 & 0,00546 & 0,45319 & 0,32516 \\
\hline 150 & 6,50321 & 0,00332 & 0,65562 & 0,32513 \\
\hline 200 & 7,08072 & 0,00201 & 0,91765 & 0,32502 \\
\hline 250 & 8,0435 & $8,5 \mathrm{E}-4$ & 1,00832 & 0,32523 \\
\hline 300 & 8,74486 & $4,1 \mathrm{E}-4$ & 1,38658 & 0,32488 \\
\hline 350 & 9,45462 & $2,2 \mathrm{E}-4$ & 1,41504 & 0,32454 \\
\hline 400 & 10,0606 & $2,9 \mathrm{E}-4$ & 1,61724 & 0,32499 \\
\hline 450 & 10,6813 & $5,3 \mathrm{E}-4$ & 1,72380 & 0,32435 \\
\hline 500 & 11,39398 & $9,6 \mathrm{E}-4$ & 1,85128 & 0,32488 \\
\hline 550 & 12,1831 & 0,00108 & 1,92126 & 0,32441 \\
\hline 600 & 12,99244 & 0,00152 & 2,02727 & 0,32506 \\
\hline
\end{tabular}

The coefficients $N u_{0 b}, \beta_{0}$ and $\beta_{1}$ given in the Table 1 are correlated as a function of the Reynolds number whereas, because of its weak variation, an average value is estimated for the coefficient $\overline{\beta_{2}}$. As shown in Figure 9, acceptable agreement is observed between the prediction using the correlation and numerical values.

\section{Conclusion}

This work has shown mixed convective heat and mass transfer inside a square ventilated enclosure. The momentum equation is solved in terms of vorticity and stream function formulation. A numerical model based on an implicit finite-difference method was developed for discretizing time average Navier-Stokes equations. The Thomas algorithm and the Gauss-Seidel iterative method were used to solve the algebraic equations. The model was applied in the simulation of a végetalised building in hot-humid climate. The numerical investigation was carried out under Togolese climate conditions. Analysis of the flow structure obtained showed a mixed convection type, but the isotherms et iso-concentration distributions reveal a vertical stratification of the temperatures and the relative humidity. To predict heat transfers inside the cavity, a correlation has been established for the estimation of the average Nusselt number as a function of the Leaf Area Index and the Reynolds number under solar heat flux of $350 \mathrm{~W} \cdot \mathrm{m}^{-2}$, the average in case of Togo. It was found that a larger Leaf Area Index reduces the solar flux penetration and therefore, reduces significantly heat transfer inside the enclosure and then stabilizes it temperature. For the LAl equal to 3 , the indoor air fluctuates around $26^{\circ} \mathrm{C}$ and the relative humidity range is found to be $50 \%$ - 
$60 \%$ under solar heat flux of $350 \mathrm{~W} \cdot \mathrm{m}^{-2}$. It is clearly proved that the foliage density and hence the vegetable canopy type selection greatly influence heat transfer inside green roof building.
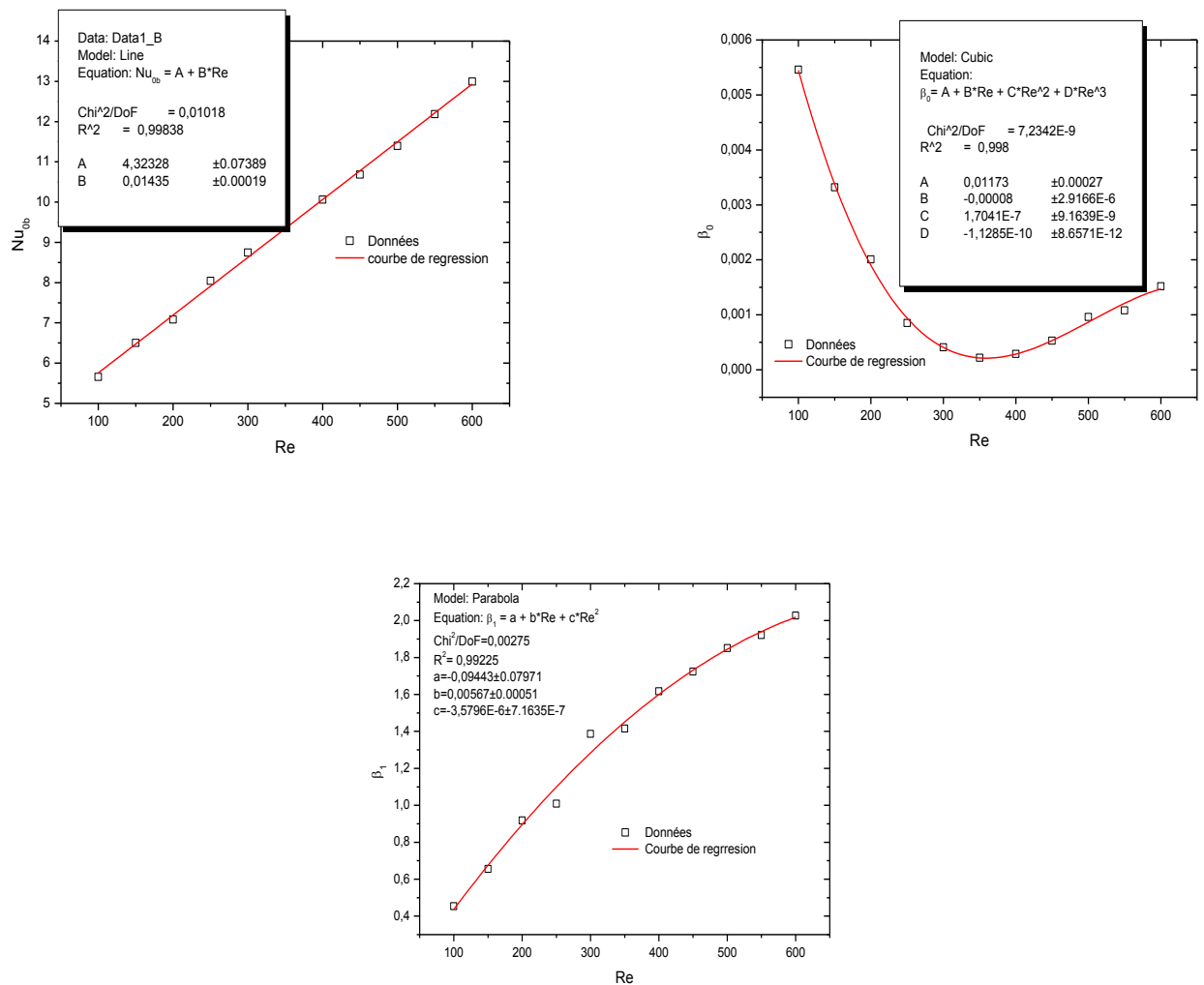

Figure 9. Regression curves of the coefficients as a function of the Reynolds number

\section{Nomenclature}

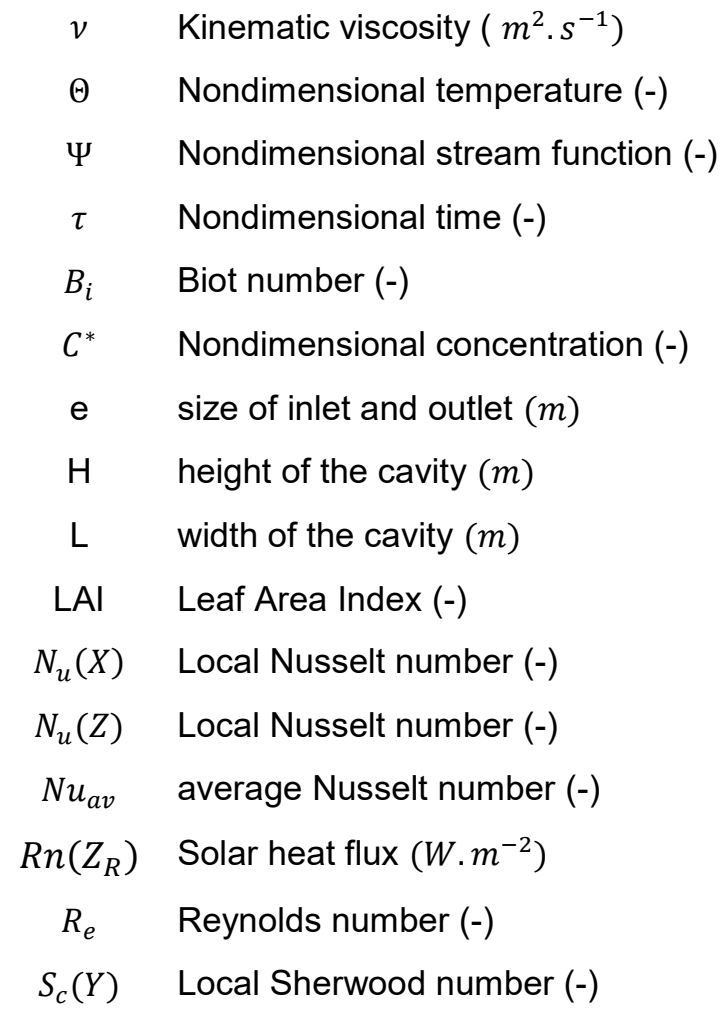

$v \quad$ Kinematic viscosity $\left(m^{2} . s^{-1}\right)$

$\Theta \quad$ Nondimensional temperature (-)

$\Psi \quad$ Nondimensional stream function (-)

$\tau \quad$ Nondimensional time (-)

$B_{i} \quad$ Biot number (-)

$C^{*} \quad$ Nondimensional concentration (-)

e size of inlet and outlet $(m)$

$\mathrm{H}$ height of the cavity $(m)$

$\mathrm{L} \quad$ width of the cavity $(\mathrm{m})$

LAI Leaf Area Index (-)

$N_{u}(X) \quad$ Local Nusselt number (-)

$N_{u}(Z) \quad$ Local Nusselt number (-)

$N u_{a v} \quad$ average Nusselt number (-)

$R n\left(Z_{R}\right) \quad$ Solar heat flux $\left(W . m^{-2}\right)$

$R_{e} \quad$ Reynolds number (-)

$S_{c}(Y) \quad$ Local Sherwood number (-) 


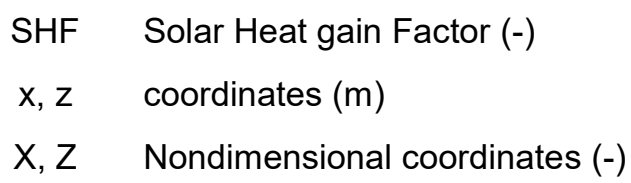

\section{References}

[1] ROOFSOL, Building in ROOFSOL, "Roof Solutions for natural cooling," . Commission of the European Communities. DG XII, Science, Research and Development; (Contract N ${ }^{\circ}$ JOR3CT960074) 1998.

[2] Nahar N, Sharma P, Purohit M. Studies on solar passive cooling techniques for arid areas. Energy Conversion and Management. 1999 01;40(1):89-95.

https://doi.org/10.1016/s0196-8904(98)00039-9

[3] Tang R, Etzion Y. On thermal performance of an improved roof pond for cooling buildings. Building and Environment. 2004 02;39(2):201-209.

https://doi.org/10.1016/j.buildenv.2003.09.005

[4] Jain D. Modeling of solar passive techniques for roof cooling in arid regions. Building and Environment. 2006 03;41(3):277-287. https://doi.org/10.1016/j.buildenv.2005.01.023

[5] Fioretti R, Palla A, Lanza L, Principi P. Green roof energy and water related performance in the Mediterranean climate. Building and Environment. 2010 08;45(8):1890-1904. https://doi.org/10.1016/j.buildenv.2010.03.001

[6] Abalo Samah H, Banna M. Performance analysis of Thermal Insulation Screens used for Classic Roofs in hot-humid Tropics. International Energy Journal. 2009;10:255-266.

[7] Niachou A, Papakonstantinou K, Santamouris M, Tsangrassoulis A, Mihalakakou G. Analysis of the green roof thermal properties and investigation of its energy performance. Energy and Buildings. 2001 09;33(7):719-729. https://doi.org/10.1016/s0378-7788(01)00062$\underline{7}$

[8] Nyuk Hien W, Puay Yok T, Yu C. Study of thermal performance of extensive rooftop greenery systems in the tropical climate. Building and Environment. 2007 01;42(1):25-54. https://doi.org/10.1016/.j.buildenv.2005.07.030

[9] Barrio EPD. Analysis of the green roofs cooling potential in buildings. Energy and Buildings. 1998 04;27(2):179-193. https://doi.org/10.1016/s0378-7788(97)00029-7

[10] Alexandri E, Jones P. Developing a one-dimensional heat and mass transfer algorithm for describing the effect of green roofs on the built environment: Comparison with experimental results. Building and Environment. 2007 08;42(8):2835-2849. https://doi.org/10.1016/j.buildenv.2006.07.004

[11] Tabares-Velasco PC, Srebric J. A heat transfer model for assessment of plant based roofing systems in summer conditions. Building and Environment. 2012 03;49:310-323. https://doi.org/10.1016/j.buildenv.2011.07.019

[12] Sailor D, Hutchinson D, Bokovoy L. Thermal property measurements for ecoroof soils common in the western U.S.. Energy and Buildings. 2008 01;40(7):1246-1251.

https://doi.org/10.1016/j.enbuild.2007.11.004

[13] Ouldboukhitine S, Belarbi R, Djedjig R. Characterization of green roof components: Measurements of thermal and hydrological properties. Building and Environment. 2012 Oct;56:78-85. https://doi.org/10.1016/j.buildenv.2012.02.024

[14] Jim C, Tsang S. Biophysical properties and thermal performance of an intensive green roof. Building and Environment. 2011 06;46(6):1263-1274.

https://doi.org/10.1016/j.buildenv.2010.12.013 
[15] Hodo-Abalo S, Banna M, Zeghmati B. Performance analysis of a planted roof as a passive cooling technique in hot-humid tropics. Renewable Energy. 2012 03;39(1):140-148. https://doi.org/10.1016/j.renene.2011.07.029

[16] Saha S, Hasan MN, Khan IA. Double Diffusive Mixed Convection Heat Transfer inside a Vented Square Cavity. Chemical Engineering Research Bulletin. 2009 Oct 05;13(1).

https://doi.org/10.3329/cerb.v13i1.2512 